\title{
Análise bibliométrica de como tem sido discutido no campo científico as interações entre as práticas de design e a produção artesanal de caráter tradicional e espontâneo.
}

Bibliometric analysis of how it has been discussed in the scientific field as interactions between traditional and spontaneous character design and production practices.

OLIVEIRA, Richitter Nasser Rosa; Graduando; Universidade do Estado de Minas Gerais

richitter.nasser@gmail.com

MARCIEL, Daniele Nayane Mariano; Graduanda; Universidade do Estado de Minas Gerais

danielenayanee@gmail.com

FREITAS, Ana Luiza Cerqueira; M.Sc; Universidade do Estado de Minas Gerais

analu.cf@hotmail.com

\section{Resumo}

A pesquisa tem o objetivo de analisar publicações acerca de pesquisas que abordem interações entre design e patrimônio, bem como interações entre design e produção artesanal de caráter espontâneo e tradicional. Para a abordagem do trabalho foram analisados diversos artigos científicos dos dois últimos anais P\&D (Congresso Brasileiro de Pesquisa e Desenvolvimento em Design) dos anos 2014 e 2016, disponíveis na base de publicações científicas da Editora Blucher, com o intuito de identificar possíveis carências de abordagem sobre a temática, além de tentar entender possíveis perspectivas e tendências encaminhadas nesta área.

Palavras Chave: Patrimônio; design; análise bibliométrica.

\begin{abstract}
The research aims at analyzing papers about the interactions between design and heritage, as well as papers about design and spontaneous, traditional crafts. To accomplish that, several papers from the Annals P\&D (Brazilian Congress of Research and Development in Design) 2014 and 2016 - available in Blucher database - were analyzed. Furthermore, this research intends to find possible gaps on the study of those interactions and to understand the trends and perspectives of the field.
\end{abstract}

Keywords: Patrimony; design; bibliometric analysis. 


\section{Introdução}

A interação entre Design e Artesanato tem aumentado nos últimos 10 anos, com a perspectiva do artesanato como campo fértil para discussão científica. Neste contexto, surgem trabalhos que unem estes dois campos de saber que começam a ganhar notoriedade no cenário brasileiro. Sendo assim, conforme apontam Freitas, Costa e Menezes (2008, p.3), "um dos primeiros pontos a serem observados é aonde se quer chegar: se essa união quer trazer conhecimento ao designer sobre novos processos, ou ao artesão sobre novas oportunidades. Essa questão define uma linha tênue entre processo e autonomia de ambos."

O produto artesanal autêntico possui alto valor agregado, em especial o valor de estima. Essa estima realiza-se em função de valores tais como, uma manifestação cultural, religiosa ou popular, o uso de matérias primas típicas de determinada região, a habilidade técnica do artesão, a tradição, uma função inerente ao contexto procedente, um saber-fazer singular e impalpável. Alguns dos saberes anteriormente úteis nas práticas diárias da nossa sociedade podem, inclusive, passar a categoria de patrimônio (FREITAS, 2011).

As singularidades têm proporcionado ascensão ao produto e ao processo produtivo artesanal. Neste sentido, o design parte em busca destas referências de materialidade, pertencimento e identidade. Começa desta forma, uma grande discussão de como fazer essa ponte, pois não estamos falando de uma assimilação de uma nova tecnologia e sim do aprendizado de um saber associado a pessoas, histórias e lugares. (FREITAS; COSTA; MENEZES, Op. Cit.)

Desta forma, tais informações tornam-se instrumentos de estudo para a proposição deste artigo no que diz respeito a procurar compreender de que maneiras integram-se o saber cultural artesanal às práticas de design, buscando assimilar que tipo de interação acontece entre estes dois universos produtivos, bem como de que maneiras têm sido discutidas no campo científico, as interações entre as práticas de design e a produção artesanal de caráter tradicional e espontâneo.

Através de abordagens em artigos, como por exemplo em "Local identity throught global design" (RIJO; SOUTO, 2014), e em "Aproximação às concepções de design e artesanato em Lina Bo Bardi e Aloísio Magalhães" (ANASTASSAKIS, 2011), percebe-se uma problemática constante na aproximação entre design e produção artesanal, no que diz respeito às ações de intervenções.

Percebe-se ainda a identificação de articulações de diálogo entre produção artesanal e industrial. Porém, mesmo de tal forma, é importante ressaltar que "o produto artesanal traz consigo uma ideia de um objeto construído com um tempo que não pode ser digital ou virtual. Na sua concepção não existe processos de produção simultânea". (FREITAS; COSTA; MENEZES, Op. cit., p.4).

Diante de percepções constatadas após a leitura de diversos autores, surgiu então a necessidade de uma análise bibliométrica que objetivasse quantificar e realizar análises de artigos publicados nos dois anais do Congresso Brasileiro de Pesquisa e Desenvolvimento em Design dos anos 2014 e 2016, disponíveis na base de publicações científicas da Editora Blucher, que tratem da temática abordada, bem como tentar entender as tendências encaminhadas nesta confluência de áreas. 


\section{Metodologia}

Utilizou-se para este estudo a técnica chamada bibliometria. Entre as aplicações da bibliometria podem ser citadas: a seleção de livros e publicações periódicas, a identificação das características temáticas da literatura, a evolução de bibliografias e coleções, entre outros. (OKUBO 1997). Neste sentido, a análise bibliométrica se torna um aporte para classificar em quantidade e qualidade as informações.

Para este trabalho, as fontes de busca adotadas foram os anais do Congresso Brasileiro de Pesquisa e Desenvolvimento em Design - P\&D, dos anos de 2014 e 2016, disponibilizados em plataforma Open Access, no site da Editora Blucher (BLUCHER PROCEEDINGS, 2017). Cumpre lembrar que o congresso P\&D é o evento de pesquisa científica em Design de maior relevância no Brasil.

Para a seleção e triagem dos dados, foram utilizadas algumas etapas (Tabela 1), como a definição da plataforma. Em seguida, foram realizadas as buscas por artigos científicos publicados nos anais P\&D 2014 e 2016, levando em conta o escopo desta pesquisa, bem como a consideração da constância em que apareciam as palavras-chave selecionadas, sendo antropologia, artesanato, bem imaterial, cultura, identidade, patrimônio e território, definidas assim por representarem aspectos condizentes ao tema "Design e Patrimônio", objeto de estudo realizado em 2017, através de pesquisa viabilizada pelo Edital 03/2017 - PAPq/UEMG. Em seguida, realizou-se a leitura de cada um dos resumos retornados, e foram analisados aqueles com maior equivalência ao conteúdo da pesquisa. Os processos foram divididos em três fases.

Tabela 1- Divisão de fases metodológicas para o levantamento bibliométrico.

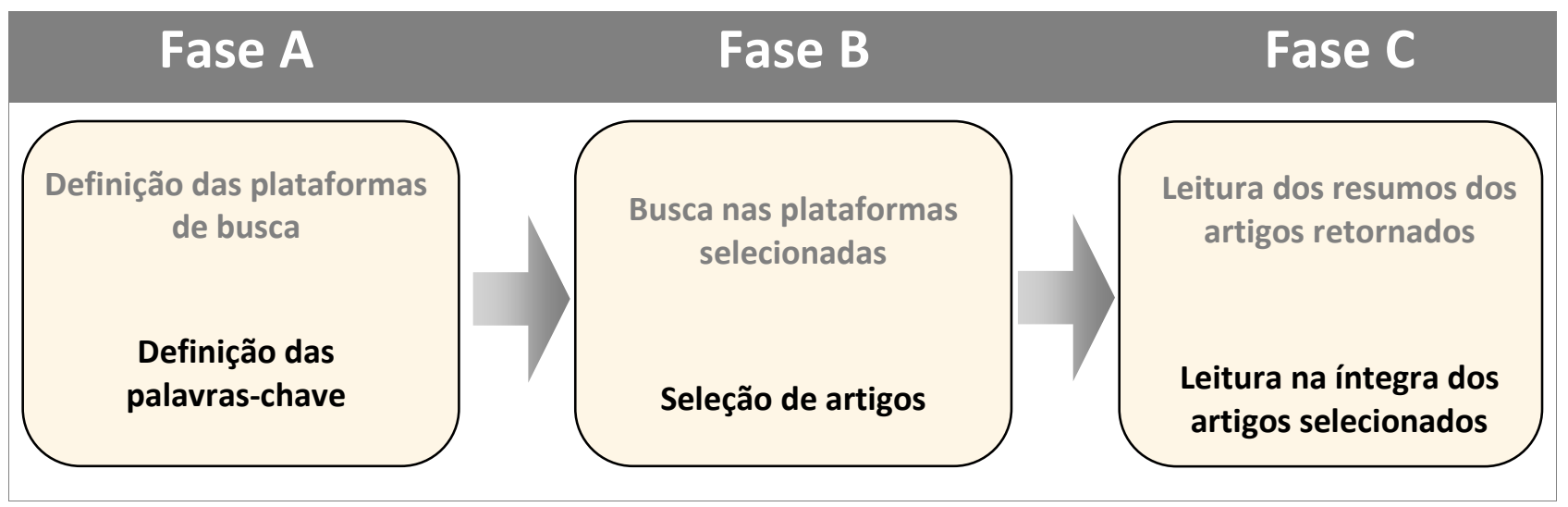

Fonte: Elaborado pelos autores (2017).

\section{Conceitos norteadores da pesquisa}

Para a elaboração deste artigo foram consideradas as definições conceituais das palavraschave adotadas pelo Instituto do Patrimônio Histórico e Artístico Nacional - IPHAN (2017), pela Organização das Nações Unidas para a Educação a Ciência e a Cultura - UNESCO (2017), Ministério da Cultura - MinC (2017), Constituição da República Federativa do Brasil e as obras "Antropologia Cultural e Social" (HOEBEL; FROST, 2000), e "Territórios em movimento: cultura e identidade como estratégia de inserção competitiva" (ALBAGLI, 2004). 


\section{Antropologia}

O conceito de Antropologia adotado para a elaboração deste artigo é entendido como antropologia cultural que, segundo a obra Antropologia Cultural e Social "trata-se das características do comportamento civilizado nas sociedades humanas passadas, presentes e futuras." (HOEBEL; FROST, 1990).

\section{Artesanato}

O Instituto do Patrimônio Histórico e Artístico Nacional entende artesanato como um ofício no tocante ao processo de produção, mas também pode entendê-lo como uma forma de expressão quando diz respeito ao caráter eminentemente artístico do produto (IPHAN, 2005).

\section{Bem imaterial}

Ainda segundo o IPHAN, os bens culturais de natureza imaterial dizem respeito àquelas práticas e domínios da vida social que se manifestam em saberes, ofícios e modos de fazer; celebrações; formas de expressão cênicas, plásticas, musicais ou lúdicas; e nos lugares, como mercados, feiras e santuários que abrigam práticas culturais coletivas (IPHAN, 2005).

\section{Cultura}

O Ministério da Cultura define a cultura em três dimensões: simbólica, cidadã e econômica. A dimensão simbólica aborda o aspecto da cultura que considera que todos os seres humanos têm a capacidade de criar símbolos que se expressam em práticas culturais diversas como idiomas, costumes, culinária, modos de vestir, crenças, criações tecnológicas e arquitetônicas, e também nas linguagens artísticas, como teatro, música, artes visuais, dança, literatura, circo, etc. A dimensão cidadã considera o aspecto em que a cultura é entendida como um direito básico do cidadão. Por fim, a dimensão econômica envolve o aspecto da cultura como vetor econômico, sendo a cultura como algo inovador e expressivo da criatividade. (MINISTÉRIO DA CULTURA, 2013).

\section{Identidade}

Segundo a Secretaria da Identidade e da Diversidade Cultural do Ministério da Cultura (2009), entende-se por identidade as manifestações características da diversidade, expressões culturais de grupos étnicos ou até expressões artísticas que contribuem sobremaneira para a diversidade.

\section{Patrimônio}

O Artigo 216 da Constituição conceitua patrimônio cultural como sendo os bens "de natureza material e imaterial, tomados individualmente ou em conjunto, portadores de referência à identidade, à ação, à memória dos diferentes grupos formadores da sociedade brasileira", nos quais se incluem as formas de expressão; os modos de criar, fazer e viver; as criações científicas, artísticas e tecnológicas; as obras, objetos, documentos, edificações e demais espaços destinados às manifestações artístico-culturais; os conjuntos urbanos e sítios de valor histórico, paisagístico, artístico, arqueológico, paleontológico, ecológico e científico. 


\section{Território}

De acordo com Albagli (2004), “o território é o espaço apropriado por um ator, sendo definido e delimitado por e a partir de relações de poder, em suas múltiplas dimensões" [material e imaterial]. Ainda segundo o autor, o território deveria "ser objeto de análise sob diferentes perspectivas - geográfica, antropológico-cultural, sociológica, econômica, jurídico-política, bioecológica, que o percebem, cada qual, segundo suas abordagens específicas".

\section{Levantamento bibliométrico: Anais P\&D 2014}

Nos anais P\&D 2014 acessível na plataforma Open Access da Editora Blucher, estão disponíveis 322 artigos, e destes, 35 artigos contemplam alguma das palavras-chave selecionadas, ou seja, cerca de $10 \%$ do total (Figura 1 ).

Figura 1: Gráfico de Análise Anais P\&D 2014

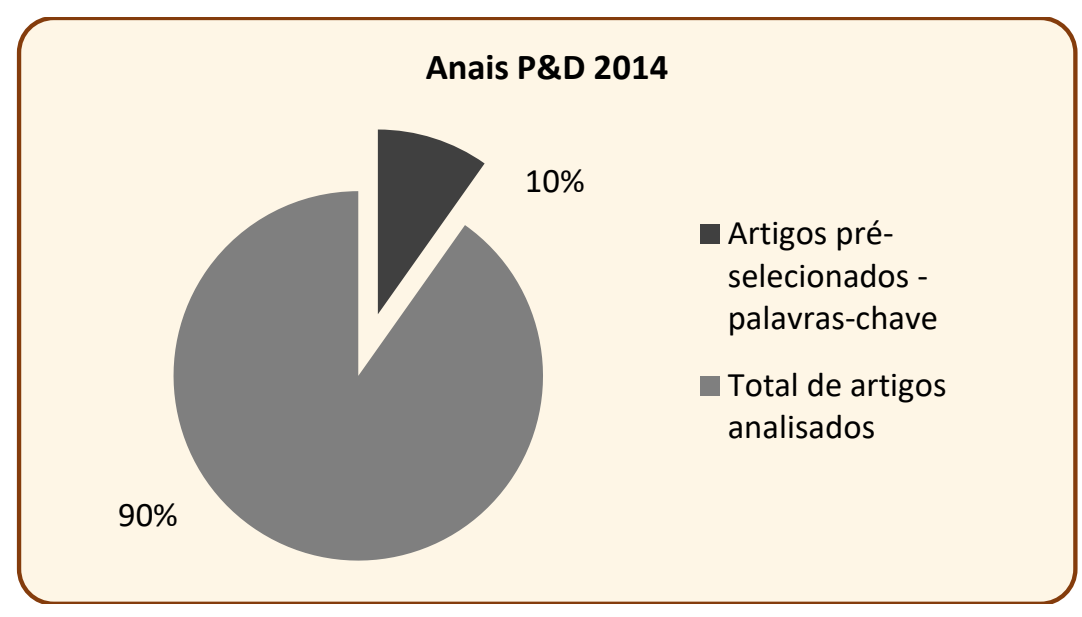

Fonte: Elaborado pelos autores (2017).

Foram consideradas as palavras-chave antropologia, artesanato, bem imaterial, cultura, identidade, patrimônio e território, conforme ilustra a Figura 2. 
Figura 2: Gráfico dos artigos analisados

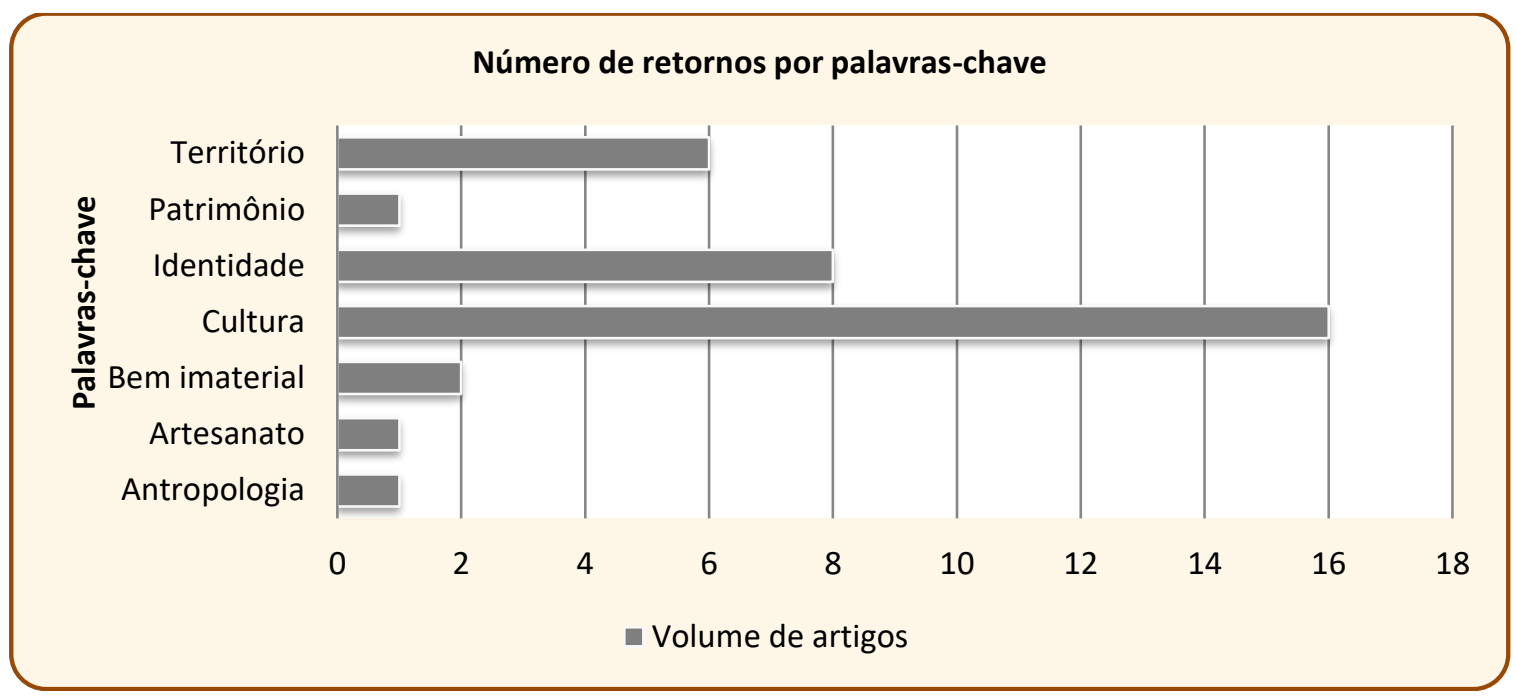

Fonte: Elaborado pelos autores (2017).

Os artigos retornados com cada uma das palavras mostram abordagens distintas entre si, e poucas abordagens do que diz respeito à semelhança com aspectos do escopo da análise em questão, conforme apresentado na Tabela 2.

Tabela 2: Número/abordagem de artigos retornados por palavras-chave - P\&D 2014.

\begin{tabular}{l|cll}
\hline Palavra-chave & $\begin{array}{c}\text { No de } \\
\text { Artigos }\end{array}$ & \multicolumn{1}{c}{ Abordagem } \\
\hline ANTROPOLOGIA & 1 & $\begin{array}{l}\text { Possibilidades de ensino do design a partir de experimentações práticas, em diálogo } \\
\text { com a perspectiva do antropólogo Tim Ingold. }\end{array}$ \\
\hline ARTESANATO & 1 & $\begin{array}{l}\text { Avaliações de análises químicas, físicas e mecânicas de massas cerâmicas a base de } \\
\text { resíduos industriais, para o uso em artesanatos do Cabo de Santo Agostinho-PE. }\end{array}$ \\
\hline BEM IMATERIAL & 2 & $\begin{array}{l}\text { Fundamentos educacionais e contextuais que nortearam a construção de um mestrado } \\
\text { em Design. }\end{array}$ \\
\hline CULTURA & 16 & $\begin{array}{l}\text { Perspectiva de discursos e práticas ligados a cooperação na produção em design. } \\
\text { cultura tipográfica para web. }\end{array}$ \\
\hline & & $\begin{array}{l}\text { Dinamismo cultural, com enfoque nos processos de interligações de realidades. } \\
\text { Aspectos relativos aos direcionamentos da educação em Design. }\end{array}$ \\
\hline
\end{tabular}




\begin{tabular}{|c|c|c|}
\hline & & $\begin{array}{l}\text { Estudo das imagens utilizadas para a confecção de material didático, para o ensino de } \\
\text { jovens e adultos. }\end{array}$ \\
\hline & & Impressão 3D na cultura do design contemporâneo. \\
\hline & & $\begin{array}{l}\text { Estudo de caso, no qual se objetivou o desenvolvimento de embalagem para micro e } \\
\text { pequenas empresas de maricultura. }\end{array}$ \\
\hline & & $\begin{array}{l}\text { Abordagem do papel do Designer nas políticas públicas culturais, e propõe relações } \\
\text { históricas entre design e tais políticas }\end{array}$ \\
\hline & & $\begin{array}{l}\text { Estudo de caso em uma favela do Rio de Janeiro, que usa do design como instrumento } \\
\text { de promoção e enriquecimento cultural. }\end{array}$ \\
\hline & & $\begin{array}{l}\text { Reflexão crítica sobre o percurso histórico do design, tecendo uma análise sobre as } \\
\text { formulações em seu conceito e fenômenos que o influenciaram na contemporaneidade }\end{array}$ \\
\hline & & $\begin{array}{l}\text { Identificar ações e estratégias do design para a valorização do território por meio da } \\
\text { cultura gastronômica. }\end{array}$ \\
\hline & & $\begin{array}{l}\text { Descrever o processo de desenvolvimento, aplicação e análise de sondas culturais por } \\
\text { uma turma de graduação de design de produto. }\end{array}$ \\
\hline & & Estudo de caso aplicado na área de design social. \\
\hline & & $\begin{array}{l}\text { Desenvolvimento de uma coleção de estampas, que serão aplicadas em bolsas, usando } \\
\text { como base conceitual elementos da cultura local. }\end{array}$ \\
\hline & & $\begin{array}{l}\text { Discutir como a sociedade conseguiu contrapor a pressão industrial, por meio de } \\
\text { movimentos artísticos. }\end{array}$ \\
\hline & & $\begin{array}{l}\text { Como os encontros culturais, compreendidos como hibridação cultural, influenciam o } \\
\text { potencial criativo das pessoas. }\end{array}$ \\
\hline IDENTIDADE & 8 & $\begin{array}{l}\text { Discussão para tentar entender a expressão das identidades visuais contemporâneas } \\
\text { nas artes gráficas. }\end{array}$ \\
\hline & & $\begin{array}{l}\text { Processo para criação de uma identidade visual para uma associação de produção de } \\
\text { cerâmica, no estado do Maranhão. }\end{array}$ \\
\hline & & Evolução histórica do Branding no Brasil. \\
\hline & & $\begin{array}{l}\text { Comportamento de uso dos idosos, diante de uma aplicação multitouch de caráter } \\
\text { lúdico. }\end{array}$ \\
\hline & & Relacionamento entre produtos de moda e a expressão da identidade. \\
\hline & & Elementos de composição de manuais de identidade visual de empresas privadas. \\
\hline & & $\begin{array}{l}\text { Discutir o papel da direção de arte na construção da identidade visual de produções } \\
\text { audiovisuais contemporâneas. }\end{array}$ \\
\hline & & Identidade cultural, em uma perspectiva de estudo de caso do ensino de Design \\
\hline
\end{tabular}




\begin{tabular}{|c|c|c|}
\hline & & partindo do conceito de identidade cultural. \\
\hline PATRIMÔNIO & 1 & $\begin{array}{l}\text { Adequação de novas tecnologias, para intervenções em sítios históricos, com uma } \\
\text { perspectiva de aplicação de tecnologias da informação para preservação patrimonial. }\end{array}$ \\
\hline \multirow{6}{*}{ TERRITÓRIO } & 6 & Valorização gastronômica. \\
\hline & & Design de ambientes como promotor de valorização cultura. \\
\hline & & Criação de uma identidade visual para uma associação de produção de cerâmica. \\
\hline & & $\begin{array}{l}\text { Discutir e explorar elementos dos processos de comunicação contidos em um mapa } \\
\text { turístico. }\end{array}$ \\
\hline & & $\begin{array}{l}\text { Investigação de multiplicidades no processo de criação em moda na } \\
\text { contemporaneidade. }\end{array}$ \\
\hline & & $\begin{array}{l}\text { Articulação de reflexões sobre as relações economia ecológica, teoria do } \\
\text { decrescimento e ações de design para o território. }\end{array}$ \\
\hline
\end{tabular}

Fonte: Elaborado pelos autores (2017).

\section{Levantamento bibliométrico: Anais P\&D 2016}

Nos anais P\&D 2016 disponível na plataforma Open Access da Editora Blucher, estão disponíveis 536 artigos, e destes, 45 artigos contemplam alguma das palavras-chave selecionadas, neste caso, cerca de $8 \%$ do total (Figura 3).

Figura 3: Gráfico de Análise Anais P\&D 2016

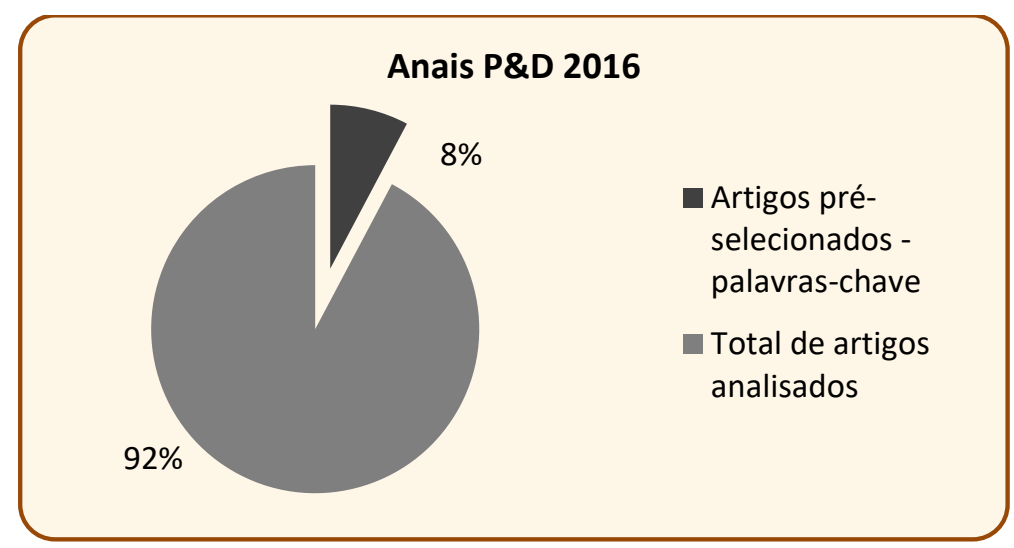

Fonte: Elaborado pelos autores (2017)

Para a busca de palavras-chave no P\&D 2016, assim como no P\&D 2014 , foram considerados os termos antropologia, artesanato, bem imaterial, cultura, identidade, patrimônio e território (Figura 4). 
Figura 4: Gráfico artigos analisados

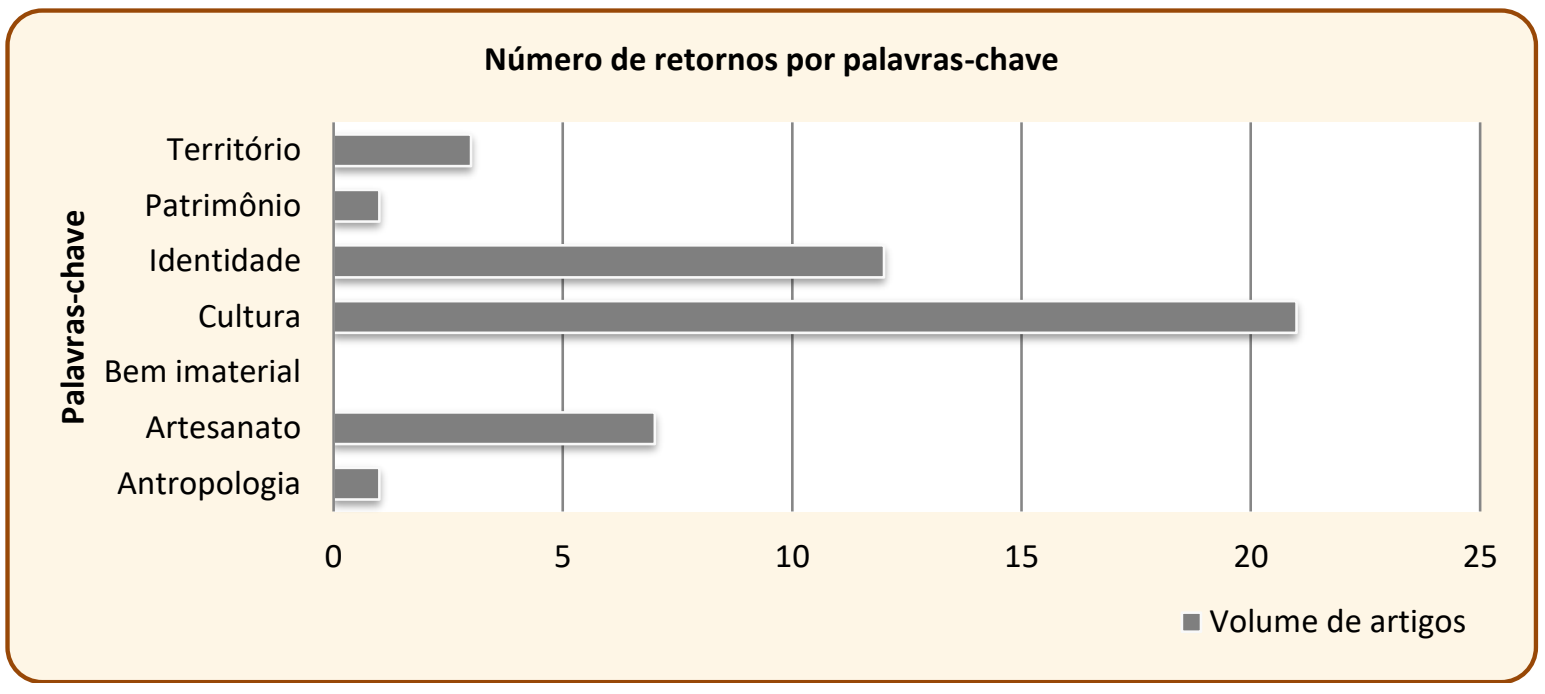

Fonte: Elaborado pelos autores (2017)

Os resultados retornados nas buscas por palavras-chave mostraram poucas abordagens com assuntos no escopo da pesquisa (Tabela 3).

Tabela 3: Tabela Número/abordagem de artigos retornados por palavras-chave - P\&D 2016

\begin{tabular}{|c|c|c|}
\hline $\begin{array}{c}\text { Palavra- } \\
\text { chave }\end{array}$ & $\begin{array}{c}\text { № de } \\
\text { Artigos }\end{array}$ & Abordagem \\
\hline \multirow[t]{2}{*}{ ANTROPOLOGIA } & 2 & Estudo da relação da civilização ocidental com as imagens. \\
\hline & & $\begin{array}{l}\text { Possíveis nexos entre Design, Antropologia Visual e o método etnográfico aplicado } \\
\text { no desenvolvimento de produtos culturais, mais especificamente, livros de } \\
\text { fotografias. }\end{array}$ \\
\hline \multirow[t]{3}{*}{ ARTESANATO } & 7 & $\begin{array}{l}\text { Apresenta a cultura da Comunidade do Artesanato do Dendê, localizada na Estrada } \\
\text { do Coco, Camaçari-BA, desde a coleta do material até a comercialização dos } \\
\text { produtos. }\end{array}$ \\
\hline & & $\begin{array}{l}\text { Descreve as tecnologias gerenciais e práticas sociais empregadas para construção de } \\
\text { um modelo de gestão para o Centro de Artesanato Wilson Campos Júnior, Cabo de } \\
\text { Santo Agostinho, PE. }\end{array}$ \\
\hline & & $\begin{array}{l}\text { Busca refletir sobre a relação design e artesanato, assim como, no horizonte } \\
\text { ontológico a relação, design e arte, articulados teoricamente pela sustentabilidade e } \\
\text { pela inovação. }\end{array}$ \\
\hline
\end{tabular}

Tem como objetivo construir um modelo de análise da cadeia produtiva do artesanato, dentro da visão da economia criativa, a partir dos referenciais de um conjunto de comunidades produtoras artesanais. 


\begin{tabular}{l|ll} 
& & $\begin{array}{l}\text { O artigo problematiza o papel desempenhado pelo artesão e pelo designer e } \\
\text { suas inter-relações e reflete sobre a delicadeza desse encontro. }\end{array}$ \\
& $\begin{array}{l}\text { Este artigo analisa a aplicação de conceitos de branding e design para o } \\
\text { desenvolvimento de um Arranjo Produtivo Local como suporte para o resgate da } \\
\text { tradição do artesanato em vime na região de Ana Rech, Caxias do Sul, RS. }\end{array}$ \\
\hline BEM IMATERIAL & $\begin{array}{l}\text { Apresenta a criação de produtos artesanais para serem produzidos por crianças e } \\
\text { jovens, filhos de quebradeiras de coco babaçu, com a finalidade de ocupá-los fora dos } \\
\text { campos. }\end{array}$ \\
\hline CULTURA & $21 \quad \begin{array}{l}\text { Objetiva identificar quais ações podem ser propostas pelo design visando à valorização } \\
\text { e identificação dos produtos da agricultura familiar. }\end{array}$ \\
\hline
\end{tabular}

Situa e identifica as ações de design no Circo Voador, espaço da cultura alternativa no Rio de Janeiro, na década de 80.

Estudo da relação da civilização ocidental com as imagens.

Verificar as questões relacionadas ao design, usabilidade e ergonomia das panelas, com vistas a melhorar a qualidade e eficiência dos produtos fabricados em Minas.

Analisa, a partir dos conceitos de Design e Território, Identidade Cultural e Multiculturalismo, as criações e as configurações elaboradas para a montagem do espetáculo "A Mandioca Brava”.

Apresenta por meio de um estudo de caso, a aplicabilidade da abordagem do design thinking no contexto cultural pernambucano.

Apresenta um resumo da dissertação de mestrado Design, Cultura Material, Artesanato e Memória defendida no Programa de Pós-Graduação em Design da PUC-Rio em 2016.

Aborda as relações estabelecidas entre a escrita alfabética e os povos indígenas do Brasil, a fim de compreender o surgimento da chamada nova escrita indígena,

Identificar de que forma a utilização dos instrumentos de metodologias do design se relacionam com a projetação, desenvolvimento e realização de um congresso de moda.

Compreender o status quo do design, no contexto da nossa realidade social, econômica e cultural.

Compreensão do estado da arte das temáticas que abrangem este cenário, bem como realizar um levantamento de ações que utilizam o design gráfico como meio de dinamizar as relações de uso do usuário com o espaço urbano.

Propõe identificar parâmetros, para aplicá-los em projetos de mobiliários urbanos e construir uma nova relação do manauara com o seu meio urbano.

Discute a relação que um forasteiro estabelece com o espaço turístico e os artefatos que se propõem a transportar a memória da experiência vivida, delimitados nesta ocasião como os suvenires. 


\begin{tabular}{|c|c|c|}
\hline & & $\begin{array}{l}\text { Trata da pesquisa e desenvolvimento de parte de um trabalho de conclusão de curso } \\
\text { em Design de Produto. }\end{array}$ \\
\hline & & Inicia discussão sobre as similaridades existentes entre a contracultura - década de 60. \\
\hline & & $\begin{array}{l}\text { Relato dos resultados obtidos pelo Labsol, Laboratório de Design Solidário, da UNESP - } \\
\text { Universidade Estadual Paulista Júlio de Mesquita Filho, Campus Bauru. }\end{array}$ \\
\hline & & $\begin{array}{l}\text { Apresenta o resultado do projeto de pesquisa "Modelo de análise da cadeia produtiva } \\
\text { do artesanato", realizado em três fases e viabilizado por editais do Funcultura - PE. }\end{array}$ \\
\hline & & $\begin{array}{l}\text { Propõe uma discussão acerca do papel do designer na sociedade diante do contexto } \\
\text { cultural em que ele se insere. }\end{array}$ \\
\hline & & $\begin{array}{l}\text { Fazer a análise da iconografia da cultura mineira em espaços gastronômicos de Belo } \\
\text { Horizonte, tais como: bares, restaurantes, cafés, mercados e feiras, afim de entender } \\
\text { as imagens que são utilizadas e as relações simbólicas e alegóricas para representação } \\
\text { da mesma. }\end{array}$ \\
\hline & & $\begin{array}{l}\text { Apresenta resultados parciais de um projeto de extensão que visa identificar, } \\
\text { registrar e difundir intervenções ao longo da Rua Aarão Reis, que compõe uma } \\
\text { região reconhecida como "Baixo Centro Cultural” da cidade de Belo Horizonte. }\end{array}$ \\
\hline & & $\begin{array}{l}\text { Estudo que incide sobre uma associação de grupos extrativistas do coco babaçu, } \\
\text { envolvendo mulheres e suas famílias, nos estados do Pará, Tocantins, Maranhão e } \\
\text { Piauí: evidencia aspectos metodológicos que posicionam os designers como } \\
\text { mediadores de processos de inclusão social. }\end{array}$ \\
\hline IDENTIDADE & 12 & $\begin{array}{l}\text { Trata do método utilizado na pesquisa intitulada "Glossário visual popular paulista: } \\
\text { artefatos memoráveis presentes em residências de famílias de origem rural no estado } \\
\text { de São Paulo". }\end{array}$ \\
\hline & & $\begin{array}{l}\text { Analise, a partir dos conceitos de Design e Território, Identidade Cultural e } \\
\text { Multiculturalismo, as criações e as configurações elaboradas para a montagem do } \\
\text { espetáculo "A Mandioca Brava". }\end{array}$ \\
\hline & & $\begin{array}{l}\text { Apresenta o relato de experiências vividas por um grupo de extensionistas da } \\
\text { Universidade Federal da Paraíba através do design colaborativo. }\end{array}$ \\
\hline & & $\begin{array}{l}\text { Apresenta o processo de conceituação de nome e identidade visual para aplicativo de } \\
\text { caronas desenvolvido em instituição pública de ensino superior, para uso exclusivo da } \\
\text { comunidade acadêmica. }\end{array}$ \\
\hline & & $\begin{array}{l}\text { Investiga processos projetuais aplicados em situações reais onde comunidades informais, } \\
\text { vulneráveis ou sem condições econômicas de contratar os serviços de escritórios de design } \\
\text { e de arquitetura e urbanismo, solicitam auxílio para demandas específicas. }\end{array}$ \\
\hline & & $\begin{array}{l}\text { Propõe identificar parâmetros, para aplicá-los em projetos de mobiliários urbanos e } \\
\text { construir uma nova relação do manauara com o seu meio urbano. }\end{array}$ \\
\hline & & $\begin{array}{l}\text { Busca analisar as relações entre moda e identidade em um contexto social, partindo da } \\
\text { teoria de Nestor Garcia Canclini sobre culturas híbridas. }\end{array}$ \\
\hline & & $\begin{array}{l}\text { Analisa a linguagem visual utilizada nas marcas gráficas das primeiras universidades } \\
\text { brasileiras: do Rio de Janeiro, do Paraná, da Bahia e de Minas Gerais. }\end{array}$ \\
\hline
\end{tabular}




\begin{tabular}{|c|c|c|}
\hline & & $\begin{array}{l}\text { Discute o papel do designer nos processo de construção de identidades de gênero } \\
\text { através de uma análise da representação de características associadas a homens e } \\
\text { mulheres em brinquedos do Grupo LEGO }{ }^{\circledR} \text {. }\end{array}$ \\
\hline & & $\begin{array}{l}\text { Apresenta a primeira parte de pesquisa voltada para o estudo de rótulos } \\
\text { cromolitográficos de produtos brasileiros, com ênfase nas estratégias técnico- } \\
\text { projetuais adotadas em sua realização. }\end{array}$ \\
\hline & & $\begin{array}{l}\text { Objetiva apresentar a pesquisa de metodologias aplicadas no projeto "Construção de } \\
\text { Identidades do Bairro Pacheco". }\end{array}$ \\
\hline & & $\begin{array}{l}\text { Pensar a relação estabelecida entre designers e comunidade, e a construção de novas } \\
\text { realidades sociais a partir da instância projetual. }\end{array}$ \\
\hline PATRIMÔNIO & 1 & $\begin{array}{l}\text { Relato os resultados obtidos pelo Labsol, Laboratório de Design Solidário, da UNESP - } \\
\text { Universidade Estadual Paulista Júlio de Mesquita Filho, Campus Bauru. }\end{array}$ \\
\hline \multirow[t]{3}{*}{ TERRITÓRIO } & 3 & $\begin{array}{l}\text { Analisa, a partir dos conceitos de Design e Território, Identidade Cultural e } \\
\text { Multiculturalismo, as criações e as configurações elaboradas para a montagem do } \\
\text { espetáculo "A Mandioca Brava". }\end{array}$ \\
\hline & & Objetiva relatar a valorização do território por intermédio do design \\
\hline & & $\begin{array}{l}\text { Apresenta a aplicação e a implicação de abordagens participativas e empáticas na } \\
\text { região de Itapoã-DF. }\end{array}$ \\
\hline
\end{tabular}

Fonte: Elaborado pelos autores (2017).

\section{Considerações Finais}

Diante dos resultados encontrados nesta análise bibliométrica, é possível perceber uma lacuna no que diz respeito às proposições de abordagens científicas com a temática da aproximação entre as práticas de design e a produção artesanal de caráter autêntico e tradicional.

As abordagens feitas no P\&D 2014 e no P\&D 2016, após buscas por cada uma das palavraschave, juntas totalizaram 858 artigos, dos quais apenas 80 deles retornaram conteúdo com as palavras- chave previamente definidas. Isto representa menos de $10 \%$ da produção científica destas duas edições de um congresso nacional de design. Cumpre observar que, destes $10 \%$, são poucos os artigos que tratam especificamente de reflexões sobre o desenvolvimento do artesanato de caráter tradicional.

Com relação aos tipos de conteúdos verificados, é possível perceber uma crescente discussão em aspectos culturais, alguns deles com proposições de trabalhos e intervenções em comunidades artesãs, a maioria com ênfase na temática identidade, especialmente a identidade cultural.

No entanto, nota-se uma carência de reflexões no que diz respeito especificamente à abordagem de aproximação entre design e patrimônio, de que maneira ela se dá, no sentido das interferências e didáticas, bem como carências de abordagens de interações entre as práticas de design e a produção artesanal autêntica do território.

Tal lacuna sinaliza uma rica e profunda oportunidade de investigação, e a necessidade de 
se trazer para o campo científico discussões sobre a temática, e possíveis encaminhamentos na área, principalmente no tocante a formas sistêmicas, integradas, sustentáveis e éticas de se unir design e tradição no segmento produtivo de base artesanal.

\section{Referências}

ALBAGLI, Sarita. Território e Territorialidade. In: LAGES, BRAGA e MORELLI. Territórios em movimento: cultura e identidade como estratégia de inserção competitiva. Brasília/DF: SEBRAE. 2004.

ANASTASSAKIS, Zoy. Aproximações às concepções de design e artesanato em Lima Bo Bardi e Aloísio Magalhães. Disponível em: <http://www.docomomobahia.org/linabobardi_50/23.pdf>. Acesso em 21 ago. 2017.

BLUCHER PROCEEDINGS. 11․ Congresso Brasileiro de Pesquisa e Desenvolvimento em Design 119. P\&D 2014. Disponível em: https://www.proceedings.blucher.com.br/article-list/11ped233/list\#articles. Acesso em: 8 maio. 2017.

BLUCHER PROCEEDINGS. 12 Congresso Brasileiro de Pesquisa e Desenvolvimento em Design 12․ P\&D 2016. Disponível em: https://www.proceedings.blucher.com.br/article-list/ped2016277/list\#articles. Acesso em 20 maio. 2017.

CONSTITUIÇÃO DA REPÚBLICA FEDERATIVA DO BRASIL. Artigo 216. 1988*. Disponível em: http://www.senado.leg.br/atividade/const/con1988/CON1988_05.10.1988/art_216_.asp. Acesso em 14 dez. 2017.

FREITAS, Ana Luiza C.; COSTA, Andreia; MENEZES, Marlette. $\mathbf{O}$ design e a produção artesanal na pós modernidade. In: 8․ Congresso Brasileiro de Pesquisa e Desenvolvimento em Design. 08 a 11 out. 2008. Anais do 8‥ Congresso Brasileiro de Pesquisa e Desenvolvimento em Design. São Paulo: Centro Universitário Senac. 2008.

FREITAS, Ana Luiza Cerqueira. Design e Artesanato: Uma experiência de inserção da metodologia de projeto de produto. São Paulo: Editora Blucher. 131 p. 2011.

HOEBEL, E. Adamson; FROST, Everett L. Antropologia Cultural e Social. 3. ed. São Paulo: Cultrix, 1990. 470p.

IPHAN. Instituto Patrimonial Histórico e Artístico. Artesanato. Minas Gerais: IPHAN. 2014.

Disponível em: <http://portal.iphan.gov.br/>. Acesso em 10 ago. 2017.

MINISTÉRIO DA CULTURA. O Ministério. Brasília: Ministério da Cultura. 2013. Disponível em: <http://www.cultura.gov.br/o-ministerio>. Acesso em 13 dez. 2017.

OKUBO, Y. Bibliometric indicators and analysis of research systems: methods and examples. Paris: OCDE/GD, 1997.

RIJO, Cátia; SOUTO, Helena. Local identity trhought global design. Disponível em: $<$ http://pdf.blucher.com.br.s3-sa-east

1.amazonaws.com/designproceedings/icdhs2014/0053.pdf>. Acesso em 10 out. 2017.

UNESCO. Patrimônio Cultural Imaterial. Brasília: Unesco. 2017. Disponível em: <http://www.unesco.org/new/pt/brasilia/culture/world-heritage/intangible-heritage/\#topPage>. Acesso em: 13 dez. 2017. 